\title{
When Does Contextual Positivity Influence Judgments of Familiarity? Investigating Moderators of the Positivity-Familiarity Effect
}

\author{
Rebecca Weil $^{a^{*}}$, Tomás A. Palma ${ }^{\mathrm{b}}$, \& Bertram Gawronski ${ }^{\mathrm{c}}$
}

${ }^{\text {a }}$ Department of Psychology, University of Hull, Cottingham Road, Hull, HU6 7RX, United Kingdom; Phone: +44-1482-466158; r.weil@hull.ac.uk; 'Corresponding author

${ }^{\mathrm{b}}$ Faculty of Psychology, University of Lisbon, Alameda da Universidade, 1649-013, Lisbon, Portugal; Phone: +351-217943867 (ext.3878); tapalma@psicologia.ulisboa.pt

${ }^{\mathrm{c}}$ Department of Psychology, The University of Texas at Austin, 108 E. Dean Keeton A8000, Austin, TX 78712-1043, USA; Phone: +1-512-471-7520; gawronski@utexas.edu 


\begin{abstract}
The positivity-familiarity effect suggests that people use positive affect as a cue to answer the question of whether they have encountered a stimulus before. Five experiments investigated this effect under various conditions. Positivity-familiarity effects were obtained irrespective of whether the task context suggested a correct answer to the question of whether a given target stimulus is familiar or unfamiliar. However, effects were less reliable when participants had a basis to assume that they had been presented with the target stimuli earlier in the same study and when they were asked to indicate whether the targets had been presented before (instead of judging them as familiar or unfamiliar). Positivity-familiarity effects were also obtained irrespective of whether affective primes were presented for short, moderate, or long durations. However, effects were less reliable for short compared to moderate and long prime presentations. Implications for the positivity-familiarity effect and other misattribution phenomena are discussed.
\end{abstract}

Keywords: affect, analytic processing, familiarity, misattribution, salience 
When people make judgments under uncertainty, they often rely on cues. For example, when trying to answer the question of whether we like a certain object, we might rely on the positive feelings associated with the fluency of processing familiar stimuli, and therefore judge objects we have encountered before as more positive. This effect is known as the mere-exposure effect (Zajonc, 1968). Similarly, when we are faced with the question of whether we have encountered a stimulus before, we might rely on the ease of processing that stimulus and interpret fluency as a cue for familiarity (Jacoby \& Kelley, 1987; Jacoby \& Whitehouse, 1989; Whittlesea \& Williams, 2000, 2001). The theoretical idea underlying both phenomena is that the experienced fluency of processing a stimulus is misattributed to a specific characteristic of that stimulus (e.g., valence, familiarity) and used to answer a question that we are otherwise unsure how to answer (see Loersch \& Payne, 2011).

The present research focuses on a conceptually related phenomenon: the positivityfamiliarity effect (e.g., Corneille, Monin, \& Pleyers, 2005; Garcia-Marques, Mackie, Claypool, \& Garcia-Marques, 2004; Housley, Claypool, Garcia-Marques, \& Mackie, 2010; Monin, 2003; Phaf \& Rotteveel, 2005). The positivity-familiarity effect suggests that people use positive affect as a cue to answer the question of whether a stimulus has been encountered before. Expanding on recent failures to replicate the phenomenon (Weil, Palma, \& Gawronski, 2017) and broader concerns about the reproducibility of social psychological effects (Open Science Collaboration, 2015), we investigated the positivity-familiarity effect under various conditions derived from extant theories of misattribution. The broader goal of this research was to identify conditions that produce reliable positivity-familiarity effects and distinguish them from conditions under which positivity-familiarity effects are weaker and less reliable. Although previous research has identified a broad range of theoretically significant moderators of the mere-exposure effect (for a 
meta-analysis, see Montoya, Horton, Vevea, Citkowicz, \& Lauber, 2017), much less is known about the boundary conditions of positivity-familiarity effects. By identifying theoretically significant moderators of the positivity-familiarity effect, the current findings provide valuable insights not only into the reproducibility of the effect under different conditions; they also impose valuable empirical constraints for extant theories of misattribution effects. Insofar as a given factor has different effects on different misattribution phenomena, such findings might question the assumption that they are driven by the same underlying mechanism.

\section{The Positivity-Familiarity Effect}

Conceptually, the positivity-familiarity effect can be interpreted as a reversed mere exposure effect, suggesting an intrinsic relationship between familiarity and positivity (Rotteveel \& Phaf, 2007). The central idea underlying this effect is that, because familiarity evokes positive affect, people may show a reverse tendency to infer familiarity from positive affect (e.g., Monin, 2003). The positivity-familiarity effect has been found for attractive faces (Corneille et al., 2005; Monin, 2003), positive words (Monin, 2003), and smiling faces (Baudouin, Gilibert, Sansone, Tiberghien, 2000; Garcia-Marques et al., 2004; Lander \& Metcalfe, 2007), which were judged as more familiar compared to less attractive faces (Corneille et al., 2005; Monin, 2003), neutral and negative words (Monin, 2003), and faces with neutral expressions (Garcia-Marques et al., 2004). These studies demonstrate that inherent positive features of stimuli (e.g., attractiveness of faces) influence judgments of familiarity (cf. Verde, Stone, Hatch, \& Schnall, 2010). However, the positivity-familiarity effect has also been found when positivity was manipulated contextually (e.g., Claypool, Hall, Mackie, \& Garcia-Marques, 2008; Garcia-Marques et al., 2004; Housley et al., 2010; Phaf \& Rotteveel, 2005). The latter findings suggest that, even when target stimuli themselves do not elicit positive affect, positive affect elicited by a different source is often 
misattributed to the familiarity of the targets. Such misattribution effects have been found when positive affect was elicited by subliminal presentations of smiley faces (Garcia-Marques et al., 2004), supra- and subliminal presentations of positive words (Phaf \& Rotteveel, 2005), contraction of the zygomaticus muscle (Phaf \& Rotteveel, 2005), and reading an article designed to induce positive mood (Claypool et al., 2008).

Weil et al. (2017) found contextually induced positivity-familiarity effects using a variant of the Affect Misattribution Procedure (AMP; Payne, Cheng, Govorun, \& Stewart, 2005). In the standard version of the AMP, participants are briefly presented with a positive or negative prime stimulus, followed by a neutral Chinese ideograph (see Murphy \& Zajonc, 1993). Participants’ task is to indicate if they find the Chinese ideograph visually more pleasant or visually less pleasant than the average Chinese ideograph. In Weil et al.’s modified AMP, participants were presented with positive, neutral, and negative primes, and asked to indicate if they find the Chinese ideograph more familiar or less familiar than the average Chinese ideograph. Results showed that ideographs preceded by positive primes were judged as more familiar compared to ideographs preceded by neutral and negative primes. These results are in line with the proposed misattribution mechanism underlying priming effects in the AMP (Gawronski \& Ye, 2014; Loersch \& Payne, 2011) and the positivity-familiarity effect (e.g., Monin, 2003).

Yet, despite the use of relatively large sample sizes, the studies by Weil et al. (2017) found a statistically significant positivity-familiarity effect only in two out of their seven experiments. In light of recent debates about the reproducibility of social psychological findings (e.g., Earp \& Trafimow, 2015; Maxwell, Lau, \& Howard, 2015; Open Science Collaboration, 2015), these results might raise concerns about the robustness of the positivity-familiarity effect. However, rather than suggesting that positivity-familiarity effects are not reproducible, Weil et al.’s (2017) 
findings might indicate that positivity-familiarity effects depend on theoretically meaningful boundary conditions (see Stroebe \& Strack, 2014; Van Bavel, Mende-Siedlecki, Brady, \& Reinero, 2016).

\section{Moderators of the Positivity-Familiarity Effect}

One condition that may influence the positivity-familiarity effect is the broader context in which stimuli are judged with respect to their familiarity. Such moderating influences of context have already been demonstrated for mere-exposure effects (e.g., Dechêne, Stahl, Hansen, \& Wänke, 2009; Freitas, Azizian, Travers, \& Berry, 2005). For example, mere-exposure effects have been found to be limited to conditions of non-analytic processing and eliminated by analytic processing (Whittlesea \& Price, 2001; see also Halberstadt, 2010; Halberstadt \& Catty, 2008). Thus, to the extent that mere-exposure effects and positivity-familiarity effects are conceptually related phenomena that are driven by the same underlying processes, positivityfamiliarity effects might similarly depend on non-analytic processing strategies (see Alexopoulos, Lemonnier, \& Fiedler, 2017).

In line with this hypothesis, Rotteveel and Phaf (2007) showed that the influence of positivity on judgments of familiarity depends on participants' mood, in that positive mood amplified and negative mood reduced positivity-familiarity effects. According to the authors, positive mood induces a non-analytic processing mode, whereas negative mood leads to an analytic mode of processing. Because analytic processing interferes with misattribution effects by reducing reliance on “gut feelings” (see Eder \& Deutsch, 2015; De Houwer \& Smith, 2013), any factor promoting analytic processing (e.g., negative mood) may reduce or eliminate positivity-familiarity effects.

These considerations might be important to understand the mixed results by Weil et al. 
(2017). In the five studies that failed to produce a significant positivity-familiarity effect, participants initially completed a stimulus exposure task that suggested a normatively accurate response to the familiarity judgments in the AMP (Experiments 1-5). A significant positivityfamiliarity effect was found only in two studies that did not include a stimulus exposure task before the AMP (Experiments 6-7). One possible interpretation of this finding is that the stimulus exposure task led to enhanced analytic processing, because the context suggested normatively accurate responses and participants might have invested cognitive effort to distinguish between familiar and unfamiliar stimuli (rather than relying on their "gut feelings"). However, any such explanation remains speculative in the absence of research with direct experimental manipulations of the relevant contextual factors. Indeed, the validity of this posthoc explanation seems questionable in light of several other studies in which similar contextual conditions had no detrimental influence on the positivity-familiarity effect. For example, GarciaMarques et al. (2004) as well as Phaf and Rotteveel (2005) found reliable positivity-familiarity effects although both studies included a stimulus exposure task prior to the familiarity judgment task. Thus, one aim of the present research was to directly test whether the positivity-familiarity effect depends on task-context conditions that do versus do not suggest a normatively accurate response to the question of whether a given stimulus is familiar or unfamiliar. To the extent that task contexts that suggest a normatively accurate response enhance analytic processing, positivity-familiarity effects should be weaker (or eliminated) under such task context conditions.

A potential explanation for the seemingly inconsistent effects of task context is that misattribution of positive affect depends on other moderators in addition to the effects of processing strategies. One such moderator might be the salience of the true source of one's 
affective response. Previous research suggests that misattribution effects are reduced or eliminated when the likelihood for source confusion is reduced, that is, when the true source is more salient than the apparent source (e.g., Claypool et al. 2008; Jones, Fazio, \& Olson, 2009; Oikawa, Aarts, \& Oikawa, 2011; Ruys, Aarts, Papies, Oikawa, \& Oikawa, 2012; White \& Knight, 1984; but see Mierop, Hütter, Stahl, \& Corneille, 2018). Thus, when positive affect is induced contextually by a prime, longer prime presentations involve higher salience of the prime, which might reduce a misattribution of prime-related affect to features of the target (see Bornstein, 1989; Murphy \& Zajonc, 1993; but see Newell, \& Shanks, 2007). This hypothesis might also explain the discrepant effects of task context in previous research. For example, previous studies that found a positivity-familiarity effect under task context conditions that presumably enhance analytic processing have used relatively short prime presentations (e.g., Garcia-Marques et al., 2004). In contrast, studies that did not find a positivity-familiarity effect under similar task context conditions have used prime presentations that were considerably longer (e.g., Weil et al., 2017). ${ }^{1}$ Consequently, another aim of the present research was to investigate the role of prime duration as a moderator of the positivity-familiarity effect.

\section{Experiment 1}

To investigate the influence of task context on the positivity-familiarity effect, we employed a bogus subliminal task (see Monin, 2003; Rotteveel \& Phaf, 2007; Westerman, Lloyd, \& Miller, 2002) to manipulate the perceived existence of a correct answer to the question of whether a given target stimulus is familiar or unfamiliar. This task allowed us to manipulate the perceived existence of a correct answer without introducing a possibility for true recognition effects. After the bogus subliminal task, participants completed a modified variant of the AMP

\footnotetext{
${ }^{1}$ Whereas Garcia-Marques et al. (2004) used prime presentation times of $30 \mathrm{~ms}$ or less, Weil et al. (2017) used prime presentation times of $75 \mathrm{~ms}$.
} 
designed to measure positivity-familiarity effects (Weil et al., 2017). Participants were told that the first part of the study would include very brief, allegedly subliminal presentations of either numbers or Chinese ideographs. Once they completed this part, they were told that the first part of the study is over. The second part of the study was purportedly unrelated to the first part and concerned with the familiarity of Chinese ideographs. That is, participants were not explicitly instructed to link the first part of the study to the second part. Because we did not present any Chinese ideographs in the first part, all ideographs in the second part were in fact novel. In the second part, participants were asked to judge the familiarity of the Chinese ideographs. Following the standard protocol of the AMP, each target ideograph in the second part was preceded by a positive, a negative, or a neutral prime. Whereas bogus subliminal presentation of numbers was assumed to be irrelevant for familiarity judgments of the Chinese ideographs, bogus subliminal presentation of Chinese ideographs should suggest the existence of normatively correct responses in the familiarity judgment task. Thus, to the extent that task contexts that suggest a normatively correct response induce analytic processing (Whittlesea \& Price, 2001), positivity-familiarity effects should be significantly weaker (or eliminated) when the bogus subliminal task ostensibly included judgment-relevant stimuli (i.e., Chinese ideographs) than when it ostensibly included judgment-irrelevant stimuli (i.e., numbers).

\section{Methods}

Participants and design. Three-hundred participants (172 female, 123 male, 3 other, 2 not reported; mean age $=40.04$ years) were recruited via Prolific Academic (see Peer, Brandimarte, Samat, \& Acquisti, 2017) to participate in a study on “visual distraction and judgment.” Participants were eligible to sign up for the experiment only if (a) their country of residence was registered as the United Kingdom, (b) they had completed at least 100 studies on Prolific 
Academic, and (c) held an approval record of at least 95\%. Participants were paid £0.84 (approx. \$1.00) for their participation. The study consisted of a 3 (Prime Valence: positive vs. neutral vs. negative) $\times 2$ (Bogus Subliminal Presentation Task: judgment-relevant vs. judgment-irrelevant) mixed design, with the first factor being manipulated within-participants and the last one between-participants. $^{2}$

Bogus subliminal presentation task. The first part of the study was introduced as being concerned with unconscious perception. Participants were informed that they will be presented with a set of Chinese symbols (judgment-relevant condition) or with a set of numbers (judgmentirrelevant condition) on a computer screen. They were further told that the stimuli will be presented subliminally, that is, "they will appear so quickly that you probably will not be able to see them or even be aware of their presence.” Participants were informed that the stimuli will be masked and that their task is to keep their eyes on the screen throughout the entire task. The task included 30 presentations of three visual masks that were presented in sequential order (the first one for $250 \mathrm{~ms}$, the second one for $35 \mathrm{~ms}$, and the last one for $250 \mathrm{~ms})$. Each of the three visual masks consisted of a rectangle, filled with different combinations of number signs, ampersands, and percentage signs. Each sequence was interspaced by a blank screen for $1000 \mathrm{~ms}$ (see Westerman et al., 2002). To keep the cover story plausible, participants were initially presented with six foil stimuli (i.e., Chinese ideographs or numbers, depending on the condition) at decreasing durations (119ms, 102ms, 85ms, 68ms, 51ms, and 34ms). They appeared instead of the second mask in the sequence of masks. These foil stimuli were not presented in the

\footnotetext{
2 The sample size for each study was determined beforehand with the requirement of at least 50 participants per cell. Slightly larger samples resulted from participants who took part in the experiment but did not request their compensation immediately after completing the study. If these participants asked for their compensation later, it was granted retroactively. Sensitivity analyses (GPower 3.1.9.2), assuming a power of $(1-\beta)=.80$, revealed that the experiments were sensitive to detect effect sizes of $\eta_{\mathrm{p}}{ }^{2}>.01$ for the main statistical effect of interest. The data for each experiment were collected in one shot without prior statistical analyses. We report all data exclusions, all manipulations, and all measures. All materials and data are available at https://osf.io/3m25w/.
} 
subsequent part of the study. The 24 remaining trials showed only the three masking stimuli without any stimuli in between.

AMP. The second part of the study was introduced as being concerned with judgments of Chinese ideographs. The procedure followed the general recommendations by Payne et al. (2005), with the exception of the familiarity judgment task. Participants were instructed to judge the familiarity of Chinese ideographs. They were told to indicate whether the Chinese ideograph seems familiar or unfamiliar. On each trial of the task, participants were first presented with a warning signal (+++) for 500ms, which was replaced by a prime stimulus of either positive, negative, or neutral valence for $75 \mathrm{~ms}$. The presentation of the prime was followed by a blank screen for $125 \mathrm{~ms}$, after which a Chinese ideograph appeared for $100 \mathrm{~ms}$. The Chinese ideograph was then replaced by a pattern mask, and participants were asked to indicate whether the Chinese ideograph seems familiar or unfamiliar to them. The pattern mask remained on the screen until participants gave their response. The next trial started immediately afterwards. As prime stimuli, we used 8 positive, 8 negative, and 8 neutral images from the International Affective Picture System (IAPS; Lang, Bradley, \& Cuthbert, 2008). The selected primes were identical to the ones used in Weil et al. (2017). Using Lang et al.’s (2008) normative data, the positive primes had a mean valence rating of $M_{\mathrm{val}}=7.41\left(S D_{\mathrm{val}}=.37\right)$, a mean arousal rating of $M_{\text {arous }}=4.10\left(S D_{\text {arous }}\right.$ $=.57)$ and a mean dominance rating of $M_{\text {dom }}=.58\left(S D_{\text {dom }}=2.67\right)$; the neutral primes had a mean valence rating of $M_{\mathrm{val}}=4.63\left(S D_{\mathrm{val}}=.13\right)$, a mean arousal rating of $M_{\text {arous }}=1.46\left(S D_{\text {arous }}=.49\right)$ and a mean dominance rating of $M_{\mathrm{dom}}=.61\left(S D_{\mathrm{dom}}=2.63\right)$; and the negative primes had a mean valence rating of $M_{\mathrm{val}}=2.88\left(S D_{\mathrm{val}}=.52\right)$, a mean arousal rating of $M_{\text {arous }}=4.40\left(S D_{\text {arous }}=.72\right)$ and a mean dominance rating of $M_{\text {dom }}=.49\left(S D_{\text {dom }}=1.32\right)$. Each prime was presented three times, summing up to a total of 72 trials. As target stimuli, we used 72 Chinese ideographs from 
Payne et al. (2005). Order of trials and prime-target combinations were randomized by the computer for each participant and organized in three blocks of 24 trials. In line with the original instructions by Payne et al. (2005), participants were told that the images can sometimes bias people's responses, and that they should try their best not to let the images bias their judgments of the Chinese ideographs.

\section{Results}

Data from two participants were not recorded due to technical problems and data from one participant were incomplete and excluded from the analysis. Following procedures by Weil et al. (2017), we also excluded data from 51 participants who used the same response key on more than $90 \%$ of the AMP trials (see Deutsch, Kordts-Freudinger, Gawronski, \& Strack, 2009). The following analysis is based on the remaining 246 participants. The proportion of familiar responses towards the ideographs served as the dependent variable. A 3 (Prime Valence) $\times 2$ (Bogus Subliminal Presentation Task) mixed ANOVA revealed a significant main effect of Prime Valence, $F(2,488)=14.60, p<.001, \eta_{\mathrm{p}}{ }^{2}=.06$, (see Figure 1 ). To specify this main effect, we conducted within-subjects ANOVAs comparing each level of Prime Valence. The analyses revealed that targets were judged as more familiar when they followed a positive prime than when they followed a negative prime, $F(1,245)=23.93, p<.001, \eta_{\mathrm{p}}{ }^{2}=.09$. Moreover, targets that followed neutral primes were judged as more familiar than targets that followed negative primes, $F(1,245)=13.75, p<.001, \eta_{\mathrm{p}}^{2}=.05$. However, judgments of targets that followed neutral primes did not significantly differ from judgments of targets that followed positive primes, $F(1,245)=2.51, p=.11, \eta_{\mathrm{p}}{ }^{2}=.01$. Counter to our predictions, the judgmental relevance of the stimuli in the bogus subliminal presentation task did not moderate the main effect of Prime Valence, $F(2,488)=.22, p=.81, \eta_{\mathrm{p}}{ }^{2}=.00$, which was statistically significant in both the 
judgment-irrelevant, $F(2,242)=7.23, p=.001, \eta_{\mathrm{p}}{ }^{2}=.06$, and the judgment-relevant condition, $F(2,246)=7.61, p=.001, \eta_{\mathrm{p}}^{2}=.06$. To reduce the possibility of false-positive results, we performed a False Detection Rate (FDR) correction (Benjamini \& Hochberg, 1995) for all analyses to correct for multiple comparisons. All statistically significant results remained significant after FDR correction.

\section{Discussion}

Experiment 1 did not confirm our hypothesis that the positivity-familiarity effect depends on the judgmental relevance of the stimuli that were allegedly presented in the subliminal presentation task. Instead, we found a significant positivity-familiarity effect regardless of whether the stimuli in the bogus subliminal presentation task were relevant or irrelevant for the familiarity judgment task. One potential interpretation of this finding is that the positivityfamiliarity effect is unaffected by analytic processing. However, another interpretation is that the current manipulation failed to produce a sufficiently strong level of analytic processing to interfere with the positivity-familiarity effect. For example, it is possible that the judgmental relevance of the stimuli in the subliminal presentation task did not influence the positivityfamiliarity effect, because our instructions treated the bogus subliminal task and the AMP task as unrelated. Experiment 2 aimed to address this question.

\section{Experiment 2}

Experiment 2 was identical to Experiment 1 with two exceptions. First, instead of being informed that the bogus subliminal presentation task included either numbers or Chinese ideographs, all participants were told that the bogus subliminal presentation task included Chinese ideographs. Second, instead of asking all participants to judge the familiarity of the ideographs, half of the participants were asked to judge the ideographs as familiar versus 
unfamiliar (as in Experiment 1), while the remaining half were asked to indicate whether the ideographs had been presented to them in the subliminal presentation task before. We assumed that direct connections between the two tasks would increase the likelihood of analytic processing due to participants’ effort to correctly identify ostensibly presented ideographs, which should reduce or eliminate the positivity-familiarity effect.

\section{Methods}

Participants and design. Three-hundred participants (189 female, 109 male, 2 not reported; mean age $=40.45$ years) were recruited via Prolific Academic. Eligibility for participation was limited to individuals who had not participated in Experiment 1. The compensation and all eligibility criteria were identical to Experiment 1 . The study consisted of a 3 (Prime Valence: positive vs. neutral vs. negative) $\times 2$ (Judgmental Task: familiar/unfamiliar vs old/new) mixed design, with the first factor being manipulated within-participants and the last one between-participants.

Procedure. The procedure and materials were identical to Experiment 1, with the exception that all participants were told that the bogus subliminal presentation task included Chinese ideographs (identical to the judgment-relevant condition in Experiment 1). Half of the participants were asked to judge the ideographs in terms of their familiarity (i.e., familiar vs. unfamiliar); the remaining half were asked to indicate whether the ideographs had been presented to them in the subliminal presentation task before (i.e., old vs. new).

\section{Results}

Data from one participant were not recorded; data from another participant were incomplete and excluded from the analysis; and one participant asked to be removed from the data set after completion of the study. In addition, data from 37 participants who used the same 
response key on more than $90 \%$ of the AMP trials were excluded from the analysis (see Deutsch et al., 2009; Weil et al., 2017). The following analysis is based on the remaining 260 participants. The proportion of familiar/old judgments served as the dependent variable. A 3 (Prime Valence) $\times 2$ (Judgmental Task) mixed ANOVA revealed no statistically significant effects (all ps $>.053$ ). Judgments of the targets did not significantly differ as a function of Prime Valence regardless of whether the targets had to be judged as familiar/unfamiliar, $F(2,238)=1.26, p=.285, \eta_{\mathrm{p}}^{2}=.01$, or as old/new, $F(2,278)=.798, p=.451, \eta_{\mathrm{p}}^{2}=.006$.

\section{Discussion}

Experiment 2 failed to obtain a significant positivity-familiarity effect regardless of whether participants judged the target stimuli as familiar/unfamiliar or old/new. Interestingly, prime valence did not influence target judgments even when the targets were judged as familiar/unfamiliar. This outcome differs from the results of Experiment 1, which obtained a significant positivity-familiarity effect under identical conditions. These conflicting findings support the concern that the positivity-familiarity effect may be more fragile than previously assumed and limited to particular contextual conditions.

A potential explanation for the inconsistent findings is that, when participants were allegedly presented with judgment-relevant stimuli in a prior task, the requirement to judge the targets as familiar/unfamiliar may be ambiguous in the sense that it can be interpreted as related or unrelated to the preceding stimulus presentation task. To the extent that the familiarity judgment task is interpreted as related to the stimulus presentation task, analytic processing may be enhanced, which should lead to an attenuation of the positivity-familiarity effect (as in Experiment 2). Yet, to the extent that the familiarity judgment task is interpreted as unrelated to the stimulus presentation task, analytic processing may be relatively low, providing conditions 
that support a misattribution of positive affect to familiarity (as in Experiment 1). A requirement to indicate whether the targets had been presented before is less ambiguous, because it explicitly refers to the stimulus presentation task. As such, it may enhance analytic processing in a more consistent fashion. We will return to this issue in Experiment 5.

\section{Experiment 3}

Experiment 3 investigated whether prime duration moderates the positivity-familiarity effect. When positivity is induced contextually by primes, longer prime presentations increase the salience of the primes, which might reduce the misattribution of prime features to the target stimuli. Conversely, shorter prime presentations decrease the salience of the primes, which might increase the misattribution of prime features to the target stimuli (e.g., Jones et al. 2009; Oikawa et al., 2011). Experiment 3 investigated the influence of prime duration on the positivityfamiliarity effect using prime presentation times of either $20 \mathrm{~ms}$ or $200 \mathrm{~ms} .{ }^{3}$ Payne et al. (2005) found no influence of prime duration and stimulus onset asynchrony (SOA) on the effect of prime valence on valence judgments of targets, with prime duration varying between $75 \mathrm{~ms}$ and 1500ms and SOAs varying between 100ms and 1500ms. Accordingly, only prime durations of less than 75 ms might have the potential to substantially increase misattribution effects. Moreover, misattribution of positivity to judgments of familiarity has been found using relatively short prime presentations of 30 ms or less (e.g., Garcia-Marques et al., 2004). Based on these findings, we chose $20 \mathrm{~ms}$ as short prime duration and $200 \mathrm{~ms}$ as long prime duration.

\footnotetext{
${ }^{3}$ Because graphic card characteristics, physical characteristics of the monitor, and monitor settings influence presentation times, $20 \mathrm{~ms}$ is only an approximation of actual presentation times. The average time of actual prime presentations in the $20 \mathrm{~ms}$ condition in Experiment 3 was $M_{\text {duration }}=19.51, S D_{\text {duration }}=6.34$.
} 


\section{Methods}

Participants and design. Three-hundred-and-three participants (117 female, 179 male, 3 other, 4 not reported; mean age $=35.47$ years) were recruited via Prolific Academic. Participants were eligible to sign up for the experiment only if their country of residence was registered as the United States. All other eligibility criteria and compensation were identical to Experiments 1 and 2. The study consisted of a 3 (Prime Valence: positive vs. neutral vs. negative) $\times 2$ (Prime Duration: 20ms vs. 200ms) mixed design, with the first factor being manipulated withinparticipants and the last one between-participants.

Procedure. The procedure was identical to Experiment 1, the only exceptions being: (a) Experiment 3 did not include a bogus subliminal presentation task prior to the AMP, and (b) primes where presented either for 20ms (short prime duration) or for 200ms (long prime duration). All participants were asked to indicate whether the Chinese ideographs seem more or less familiar than an average Chinese ideograph.

\section{Results}

Data from four participants were incomplete and excluded from the analysis. In addition, we excluded data from 13 participants who used the same response key on more than $90 \%$ of the AMP trials (see Deutsch et al., 2009; Weil et al., 2017). The following analysis is based on the remaining 286 participants. The proportion of familiar responses towards the ideographs served as the dependent variable. A 3 (Prime Valence) $\times 2$ (Prime Duration) mixed ANOVA revealed a marginally significant main effect of Prime Valence, $F(2,568)=2.61, p=.08, \eta_{\mathrm{p}}{ }^{2}=.01$, qualified by a significant two-way interaction of Prime Valence and Prime Duration, $F(2,568)=$ 4.77, $p=.009, \eta_{\mathrm{p}}{ }^{2}=.02$, (see Figure 3). Separate within-subjects ANOVAs within the short prime duration condition and the long prime duration condition revealed that the main effect of 
Prime Valence was significant for long prime duration, $F(2,276)=4.94, p=.008, \eta_{\mathrm{p}}{ }^{2}=.04$, but not for short prime duration, $F(2,292)=.30, p=.74, \eta_{\mathrm{p}}{ }^{2}=.00$. For the long prime duration condition, within-subjects ANOVAs comparing each level of Prime Valence further revealed that targets were judged as more familiar when they followed a positive prime than when they followed a negative prime, $F(1,138)=7.23, p=.008, \eta_{\mathrm{p}}{ }^{2}=.05$. Moreover, targets that followed neutral primes were judged as more familiar than targets that followed negative primes, $F(1$, $138)=4.15, p=.04, \eta_{\mathrm{p}}{ }^{2}=.03$. However, judgments of targets that followed neutral primes did not differ from judgments of targets that followed positive primes, $F(1,138)=1.41, p=.24, \eta_{\mathrm{p}}{ }^{2}$ $=.01$. All statistically significant results remained significant after FDR correction, the only exception being the comparison between targets that followed neutral primes and targets that followed negative primes in the long prime duration condition.

\section{Discussion}

Contrary to our predictions, long prime presentations led to a stronger (rather than weaker) positivity-familiarity effect than short prime presentations, the latter of which eliminated the positivity-familiarity effect. This finding stands in contrast to the idea that long prime presentations, compared to short prime presentations, increase the salience of the primes, which might interfere with a misattribution of prime features to the target stimuli. The results of Experiment 3 are inconsistent with this hypothesis, and instead suggest that the positivityfamiliarity effect is more pronounced for long compared to short prime presentations.

A potential explanation of this unexpected finding is that long presentations of the primes elicit stronger affective reactions compared to short presentations. Thus, to the extent that effects of positive affect on judgments of familiarity increase as a function of affect strength, long prime presentations may lead to stronger positivity-familiarity effects compared to short prime 
presentations. Experiment 4 aimed to address this possibility by comparing effects of prime valence on judgments of target familiarity and target valence.

\section{Experiment 4}

To investigate the presumed role of affect strength in the effect of prime duration on the positivity-familiarity effect, Experiment 4 aimed to replicate the unexpected findings of Experiment 3, including an additional valence judgment condition. To the extent that the effects of prime duration in Experiment 3 are due to differences in affect strength, effects of prime valence on target judgments should increase as a function of prime duration regardless of whether the targets have to be judged in terms of their familiarity or in terms of their valence.

\section{Methods}

Participants and design. Six-hundred-and-nine participants (315 female, 281 male, 7 other, 6 not reported; mean age $=35.47$ years) were recruited via Prolific Academic. Eligibility for participation was limited to individuals who had not participated in Experiment 3. The compensation and all other eligibility criteria were identical to Experiment $3 .^{4}$ The study consisted of a 3 (Prime Valence: positive vs. neutral vs. negative) $\times 2$ (Prime Duration: 20ms vs. 200ms) $\times 2$ (Task: valence judgment vs. familiarity judgment) mixed design, with the first factor being manipulated within-participants and the last two factors between-participants. ${ }^{5}$

AMP. The procedure was largely identical to Experiment 3, the only exception being the additional manipulation of the judgment task. In the valence-judgment condition, participants’ task was to indicate whether they considered the Chinese ideographs as more pleasant or less

\footnotetext{
${ }^{4}$ After collecting the data of 132 participants with the eligibly criterion of having completed at least 100 studies on Prolific Academic, we had to lower the criterion to at least 10 studies to increase the pool of potential participants.

${ }^{5}$ The average time of actual prime presentations in the $20 \mathrm{~ms}$ condition in Experiment 4 was $M_{\text {duration }}=18.94$, $S D_{\text {duration }}=7.11$.
} 
pleasant than the average Chinese ideograph. In the familiarity-judgment condition, participants' task was to indicate whether they considered the Chinese ideograph as more familiar or less familiar than the average Chinese ideograph.

\section{Results}

Data from nine participants were incomplete and excluded from the analysis. In addition, we excluded data from 27 participants who used the same response key on more than $90 \%$ of the AMP trials (see Deutsch et al., 2009; Weil et al., 2017). The following analysis is based on the remaining 573 participants. The proportion of pleasant/familiar responses towards the ideographs served as the dependent variable. A 3 (Prime Valence) $\times 2$ (Prime Duration) $\times 2$ (Task) mixed ANOVA revealed a significant main effect of Prime Valence, $F(2,1138)=51.46, p<.001, \eta_{\mathrm{p}}{ }^{2}=$ .08 , a significant main effect of Task, $F(1,569)=23.89, p<.001, \eta_{\mathrm{p}}{ }^{2}=.04$, a significant twoway interaction of Prime Valence and Prime Duration, $F(2,1138)=6.85, p=.001, \eta_{\mathrm{p}}{ }^{2}=.01$, and a significant two-way interaction of Prime Valence and Task, $F(2,1138)=19.08, p<.001$, $\eta_{\mathrm{p}}{ }^{2}=.01$. These effects were qualified by a significant three-way interaction of Prime Valence, Prime Duration, and Task, $F(2,1138)=4.24, p=.02, \eta_{\mathrm{p}}{ }^{2}=.01$ (see Figure 4). To decompose this interaction, we conducted separate 2 (Prime Valence) $\times 2$ (Prime Duration) ANOVAs for the valence-judgment and familiarity-judgment condition, respectively.

In the valence-judgment condition, the ANOVA revealed a significant main effect of Prime Valence, $F(2,568)=50.19, p<.001, \eta_{\mathrm{p}}{ }^{2}=.15$, qualified by a significant two-way interaction of Prime Valence and Prime Duration, $F(2,568)=8.24, p<.001, \eta_{\mathrm{p}}{ }^{2}=.03$. Although the main effect of Prime Valence was statistically significant in both the short prime duration condition, $F(2,268)=15.22, p<.001, \eta_{\mathrm{p}}{ }^{2}=.10$, and the long prime duration condition, $F(2,300)=37.51$, $p<.001, \eta_{\mathrm{p}}{ }^{2}=.20$, the effect of Prime Valence was considerable larger for long compared to 
short prime presentations, as indicated by the significant two-way interaction. Separate withinsubjects ANOVAs comparing each level of Prime Valence within the short prime duration condition and the long prime duration condition further revealed that, in the short prime presentation condition, targets were evaluated more favorable when they followed positive primes than when they followed negative primes, $F(1,134)=24.46, p<.001, \eta_{\mathrm{p}}{ }^{2}=.15$. Targets that followed neutral primes were evaluated more favorable than targets that followed negative primes, $F(1,134)=12.18, p=.001, \eta_{\mathrm{p}}^{2}=.08$, and evaluations of targets that followed neutral primes where less favorable than evaluations of targets that followed positive primes, $F(1,134)=$ $6.15, p=.014, \eta_{\mathrm{p}}{ }^{2}=.04$. Moreover, in the long prime presentation condition, targets were evaluated more favorable when they followed positive primes than when they followed negative primes, $F(1,150)=49.96, p<.001, \eta_{\mathrm{p}}{ }^{2}=.25$. Targets that followed neutral primes were evaluated more favorable than targets that followed negative primes, $F(1,150)=29.44, p<.001$, $\eta_{\mathrm{p}}{ }^{2}=.16$, and evaluations of targets that followed neutral primes where less favorable than evaluations of targets that followed positive primes, $F(1,150)=19.99, p<.001, \eta_{\mathrm{p}}{ }^{2}=.12$. In the familiarity-judgment condition, the ANOVA revealed a significant main effect of Prime Valence, $F(2,570)=5.88, p=.003, \eta_{\mathrm{p}}{ }^{2}=.02$. Within-subjects ANOVAs comparing each level of Prime Valence further indicated that targets were judged as more familiar when they followed positive primes than when they followed negative primes, $F(1,286)=11.37, p=.001$, $\eta_{\mathrm{p}}{ }^{2}=.04$. Targets following neutral primes were judged marginally less familiar than targets following positive primes, $F(1,286)=3.79, p=.053, \eta_{\mathrm{p}}{ }^{2}=.01$, and did not differ from target judgments following negative primes, $F(1,286)=2.34, p=.13, \eta_{\mathrm{p}}{ }^{2}=.01$. The interaction of Prime Valence and Prime Duration was not statistically significant, $F(2,570)=.26, p=.77, \eta_{\mathrm{p}} 2$ $=.00$. All statistically significant results remained significant after FDR correction. 


\section{Discussion}

Consistent with the post-hoc interpretation of prime duration effects in terms of affect strength, long prime presentations led to stronger effects of prime valence on judgments of target valence than short prime presentations. Yet, prime duration did not moderate the effect of prime valence on judgments of target familiarity. Together with the findings of Experiment 3, these findings suggest that the positivity-familiarity effect is reliable for long prime presentations and more fragile (but not necessarily eliminated) for short prime presentations. To further explore the role of prime duration and relate it to the obtained effects of task context in Experiments 1 and 2, Experiment 5 combined a within-subjects manipulation of prime-duration with a manipulation of task context.

\section{Experiment 5}

The aim of Experiment 5 was two-fold: (a) to further explore the impact of prime duration on the positivity-familiarity effect using a within-participant manipulation and (b) to shed further light on the influence of task context on the positivity-familiarity effect, as investigated in Experiments 1 and 2. To this end, the task context manipulation in Experiment 5 combined the judgment-irrelevant condition from Experiment 1 (using numbers in the bogus subliminal presentation task and familiar/unfamiliar judgments in the AMP) with the judgment-relevant condition from Experiment 2 (using Chinese ideographs in the bogus subliminal presentation task and old/new judgments in the AMP). Whereas in the former condition, there is no basis for participants to assume a normatively accurate response to the targets in the AMP (which should promote non-analytic processing), the latter condition unambiguously suggests the existence of a normatively accurately response to the targets (which should promote analytic processing). Based on the results of the preceding studies, we expected to observe stronger positivity- 
familiarity effects (a) when the task context is judgment-irrelevant than when it is judgmentrelevant and (b) when prime presentations are long rather than short.

\section{Methods}

Participants and design. Three-hundred-and-four participants (117 female, 183 male, 2 other, 2 not reported; mean age $=32.04$ years) were recruited via Prolific Academic. Eligibility for participation was limited to individuals who had not participated in Experiments 3 and 4. Participants were eligible to sign up for the experiment if they had completed at least 10 studies on Prolific Academic; all other eligibility criteria were identical to Experiment 3 and 4. Participants were paid £1.25 (approx. \$1.50) for their participation. The study consisted of a 3 (Prime Valence: positive vs. neutral vs. negative) $\times 2$ (Prime Duration: $20 \mathrm{~ms}$ vs. $200 \mathrm{~ms}$ ) $\times 2$ (Task Context: judgment-relevant vs. judgment-irrelevant) mixed design, with the first two factors being manipulated within-participants and the last factor between-participants. ${ }^{6}$

Bogus subliminal presentation task. Participants were informed that they will be presented with a set of Chinese symbols (judgment-relevant condition) or with a set of numbers (judgment-irrelevant condition) on a computer screen. The procedural details of the bogus subliminal presentation task were identical to Experiment 1.

AMP. The procedural details of the AMP were identical to Experiment 1, the only exception being that prime duration was manipulated within-participants. Each prime (8 positive, 8 negative, 8 neutral) was shown six times to participants, three times for $20 \mathrm{~ms}$ and three times for $200 \mathrm{~ms}$, summing up to a total of 144 trials. Accordingly, 144 Chinese ideographs were used as target stimuli. The order of trials and prime-target combinations were randomized by the computer for each participant and organized in three blocks of 48 trials. In the judgment-relevant

\footnotetext{
${ }^{6}$ The average time of actual prime presentations in the $20 \mathrm{~ms}$ condition in Experiment 5 was $M_{\text {duration }}=19.68$, $S D_{\text {duration }}=9.32$.
} 
condition, participants were asked to indicate whether Chinese ideographs are old/new. In the judgment-irrelevant condition, participants were asked to judge whether Chinese ideographs seem familiar/unfamiliar.

\section{Results}

Data from four participants were incomplete and excluded from the analysis. In addition, we excluded data from 19 participants who used the same response key on more than $90 \%$ of the AMP trials (see Deutsch et al., 2009; Weil et al., 2017). The following analysis is based on the remaining 281 participants. The proportion of old/familiar responses towards the ideographs served as the dependent variable. A 3 (Prime Valence) $\times 2$ (Prime Duration) $\times 2$ (Task Context) mixed-model ANOVA revealed a significant main effect of Prime Valence, $F(2,558)=5.42, p=$ $.005, \eta_{\mathrm{p}}{ }^{2}=.02$, qualified by a significant two-way interaction of Prime Valence and Task Context, $F(2,558)=6.80, p=.001, \eta_{\mathrm{p}}^{2}=.02$ (see Figure 5).

In the judgment-irrelevant condition, there was a significant main effect of Prime Valence, $F(2,276)=8.73, p<.001, \eta_{\mathrm{p}}{ }^{2}=.06$, and this main effect was statistically significant in both the long presentation condition, $F(2,276)=7.36, p=.001, \eta_{\mathrm{p}}^{2}=.05$, and the short presentation condition, $F(2,276)=3.45, p=.033, \eta_{\mathrm{p}}{ }^{2}=.02$. Whereas the former effect remained significant after FDR correction, the latter effect was only marginally significant after FDR correction. Within-subjects ANOVAs comparing each level of Prime Valence further revealed that targets were judged as more familiar when they followed positive primes than when they followed negative primes, $F(1,138)=13.41, p<.001, \eta_{\mathrm{p}}{ }^{2}=.09$. Moreover, targets that followed positive primes were judged as more familiar than targets that followed neutral primes, $F(1,138)=10.42$, $p=.002, \eta_{\mathrm{p}}{ }^{2}=.07$. However, judgments of targets that followed neutral primes did not differ from judgments of targets that followed negative primes, $F(1,138)=1.82, p=.18, \eta_{\mathrm{p}}{ }^{2}=.01$. 
In the judgment-relevant condition, the main effect of Prime Valence was marginally significant, $F(2,282)=2.96, p=.05, \eta_{\mathrm{p}}{ }^{2}=.02$, and non-significant after FDR correction.

The omnibus ANOVA also revealed a theoretically uninteresting main effect of Prime Duration, $F(1,279)=4.76, p=.03, \eta_{\mathrm{p}}^{2}=.02$. More importantly, neither the two-way interaction between Prime Valence and Prime Duration, $F(2,558)=.21, p=.81, \eta_{\mathrm{p}}^{2}=.001$, nor the threeway interaction of Prime Valence, Prime Duration, and Task Context were statistically significant, $F(2,558)=1.46, p=.23, \eta_{\mathrm{p}}{ }^{2}=.01$. Unless indicated otherwise, all statistically significant effects remained significant after FDR correction.

\section{Discussion}

In line with our predictions, Experiment 5 showed a significant positivity-familiarity effect only when the task context did not suggest the existence of normatively accurate responses to the targets in the familiarity judgments task. In the current study, a significant positivity-familiarity effect emerged only when participants were allegedly presented with numbers in the subliminal presentation task and then judged the Chinese ideographs in the AMP as familiar or unfamiliar. In contrast, there was no evidence for a positivity-familiarity effect when participants were allegedly presented with Chinese ideographs in the subliminal presentation task and then judged the Chinese ideographs in the AMP as old or new. Consistent with the results of Experiment 4, but inconsistent with the results of Experiment 3, prime duration did not influence the positivityfamiliarity effect. When the task context did not suggest the existence of normatively accurate responses to the targets, prime valence influenced familiarity judgments of the targets regardless of whether the primes were presented for long or short durations.

\section{Bayes Factor Analysis on Combined Data}

Because Experiments 1, 2, and 5 revealed inconsistent results with respect to the role of 
task context and Experiments 3, 4, and 5 revealed inconsistent results with respect to the role of prime duration, we conducted integrative data analyses (Curran \& Hussong, 2009) using (a) the combined data from Experiments 1, 2, and 5, collapsing over prime duration conditions and (b) the combined data from Experiments 3, 4 and 5, collapsing over the task context conditions, excluding the valence judgment condition. Using the combined data sets, we calculated Bayes factors (BF; see Table 1), using JASP (2018) and the BayesFactor package (Morey \& Rouder, 2018) in the statistical software R Version 3.5.1 for Windows (R Core Team, 2018) to quantify the evidence for the presence or absence of effects. We adopted the convention that $\mathrm{BF}_{10}=1$ implies lack of any evidence (i.e., the data are as likely to occur under $\mathrm{H} 0$ as under $\mathrm{H} 1$ ), $1<\mathrm{BF} 10$ $\leq 3$ implies anecdotal evidence for $\mathrm{H} 1,3<\mathrm{BF}_{10} \leq 10$ implies moderate evidence for $\mathrm{H} 1,10<$ $\mathrm{BF}_{10} \leq 30$ implies strong evidence for $\mathrm{H} 1,30<\mathrm{BF}_{10} \leq 100$ implies very strong evidence for $\mathrm{H} 1$ and $\mathrm{BF}_{10}>100$ implies decisive evidence for H1 (Jeffreys, 1961; Lee \& Wagenmakers, 2013). Conversely, . $30<\mathrm{BF}_{10} \leq 1$ implies anecdotal evidence for $\mathrm{H} 0, .10<\mathrm{BF}_{10} \leq .30$ implies moderate evidence for $\mathrm{H} 0, .03<\mathrm{BF}_{10} \leq .10$ implies strong evidence for $\mathrm{H} 0, .01<\mathrm{BF}_{10} \leq .03$ implies very strong evidence for $\mathrm{H} 0$ and $\mathrm{BF}_{10}<.01$ implies decisive evidence for $\mathrm{H} 0$.

The combined analysis of Experiments 1, 2, and 5 showed decisive evidence for a main effect of Prime Valence and moderate evidence for no interaction between Prime Valence and Task Context (see Table 1). The combined analysis of Experiments 3, 4, and 5 showed decisive evidence for a main effect of Prime Valence and decisive evidence for no interaction between Prime Valence and Prime Duration (see Table 1). Thus, the results of the combined analysis suggest that Prime Duration does not moderate positivity-familiarity effects and that effects can be found for long and short prime presentations. Moreover, moderate evidence exists that Task Context does not moderate positivity-familiarity effects and that effects can be found in contexts 
that do and do not suggest a normatively accurate response to the question of whether a given stimulus is familiar or unfamiliar.

\section{General Discussion}

The aim of the current research was to identify conditions that produce reliable positivityfamiliarity effects and distinguish them from conditions under which positivity-familiarity effects are weaker and less reliable. Toward this end, we utilized a modified variant of the AMP (Payne et al., 2005) and investigated whether prime valence influences judgments of target familiarity under various conditions. Table 2 provides an overview of the results obtained in the current studies. Across the five studies, positivity-familiarity effects were obtained when participants had no basis to assume that they had been presented with the target stimuli earlier in the same study, the targets had to be judged in terms of their familiarity (rather than whether the targets had been presented before), and when affective primes were presented for moderate (75ms) to long (200ms) rather than short (20ms) durations. Effects were more fragile when participants judged the targets in terms of their familiarity, but had a basis to assume that the targets might have been presented before or when the primes were presented for short durations. No significant positivity-familiarity effects were obtained when participants had a basis to assume that they had been presented with targets earlier and had to judge whether targets had been presented to them before. Nevertheless, Bayes Factor analyses on the combined data from Experiments 1, 2, and 5 and Experiments 3, 4, and 5, respectively, suggest that positivityfamiliarity effects are relatively robust overall and not moderated by prime duration and by a task context that does or does not suggest a normatively accurate response to the question of whether a given stimulus is familiar or unfamiliar.

The latter finding stands in contrast to speculations that the positivity-familiarity effect 
may depend on conditions in which the task context does not suggest the existence of normatively accurate responses in the familiarity task (Weil et al., 2017). This speculation was based on the assumptions that (a) an alleged stimulus exposure task might enhance analytic processing, and (b) misattribution of affective responses is more pronounced under conditions of non-analytic processing and reduced by analytic processing (Eder \& Deutsch, 2015; De Houwer \& Smith, 2013; Rotteveel \& Phaf, 2007). Although the results of the individual experiments (Experiments 1, 2, 5) suggest that particular contextual features might be more likely to prevent analytic processing (i.e., not providing participants with a basis to assume prior presentation of target stimuli) than others (i.e., judging targets in terms of general familiarity, rather than whether they had been presented before), the results of the combined Bayesian analysis suggest that the present manipulation of task context was not successful in clearly differentiating between analytical and non-analytical processing. While this interpretation seems to be in line with research demonstrating positivity-familiarity effects despite the existence of a normatively accurate response (see Monin, 2003; Rotteveel \& Phaf, 2007), it reopens the question of what prevented the occurrence of positivity-familiarity effects under similar conditions in earlier studies (Weil et al., 2017).

A further aim of the present study was to shed light on seemingly inconsistent results in the literature on the positivity-familiarity effect. Whereas some studies suggest that alleged presentations of the target stimuli in a prior task eliminate the positivity-familiarity effect (Weil et al., 2017), other studies found no such detrimental influences (e.g., Garcia-Marques et al., 2004; Phaf \& Rotteveel, 2005). We speculated that other determinants of misattribution effects might carry more weight when the task context suggests a normatively accurate response and identified prime salience as one such determinant. Specifically, we hypothesized that long prime 
presentations increase the salience of the primes, which may reduce the misattribution of prime features to the targets (e.g., Murphy \& Zajonc, 1993; White \& Knight, 1984). However, counter to this hypothesis, Experiment 3 showed that positivity-familiarity effects occurred only for long (200ms) but not for short (20ms) prime presentations (for related findings, see Gellatly, Banton, \& Woods, 1995; Newell \& Shanks, 2007). Moreover, the results of the combined Bayesian analysis suggest that prime duration does not moderate positivity-familiarity effects at all.

The obtained effects of prime duration may indicate that the attribution of positivity to familiarity may be less dependent on source confusion than suggested by extant accounts. In this case, positivity-familiarity effects may result from a deliberate choice to use content activated by one source to make judgments about another source. In line with this interpretation, some studies suggest that attributions of familiarity to positivity are enhanced when familiar stimuli are recognized (Newell \& Shanks, 2007) and the attribution of affect to a neutral source seems more likely when affect was more intense (as compared to less intense affective stimuli; Mierop et al., 2018). Such an explanation for the present and related findings might have further implications for social psychological phenomena assumed to be driven by misattribution, raising the question of whether at least some of these phenomena occur despite an identification of true sources. Future research should aim to identify the conditions under which people choose to use content activated by one source to make judgments about another source.

Although the current research found relatively robust positivity-familiarity effects, it is worth noting that the observed effects of prime valence on judgments of target familiarity were relatively small with effect sizes ranging from $\eta_{\mathrm{p}}{ }^{2}=.02$ to $\eta_{\mathrm{p}}{ }^{2}=.06$. Effects of prime valence on judgments of target valence were considerable larger with effect sizes ranging from $\eta_{\mathrm{p}}{ }^{2}=.10$ to $\eta_{\mathrm{p}}{ }^{2}=.20$ (see Experiment 4). Thus, failures to replicate the positivity-familiarity effect can be 
due to insufficient statistical power in identifying relatively small effects of prime valence on judgments of target familiarity (Maxwell et al., 2015). The current work anticipated potential concerns in this regard by using sample sizes that were considerable larger compared to the ones in previous studies on the positivity-familiarity effect. Yet, even large sample sizes may sometimes be insufficient (e.g., Weil et al., 2017). Thus, future research should further aim to identify conditions under which positivity-familiarity effects become fragile and conditions that produce reliable positivity-familiarity effects.

As a caveat, we should note that in Experiments 1, 2, 3, and 4 we required that participants had completed at least 100 studies on Prolific Academic (Palan, \& Schitter, 2018; Peer et al., 2017). This criterion was used to ensure that the required approval record of $95 \%$ referred to a sensible base-rate and that the quality of obtained data would be high. However, this criterion includes a trade-off between naivety of participants and data quality. We did not anticipate any effects of familiarity with psychological experimental paradigms on the effects of interest in the present study. In Experiments 4 and 5, we used a more lenient eligibility criterion of having completed at least 10 studies on Prolific Academic. Our procedure of excluding participants who used the same response key on more than $90 \%$ of the AMP trials is assumed to mitigate this more lenient criterion.

\section{Future Directions}

To the extent that the positivity-familiarity effect is closely related to fluency-familiarity effects (e.g., Winkielman, Schwarz, Fazendeiro, \& Reber, 2003), well-known moderators of fluency-familiarity effects might also moderate positivity-familiarity effects. For example, it has been found that fluency effects are relative in the sense that they are sensitive to expectations of experienced fluency (Westerman, 2008; Whittlesea \& Leboe, 2003). Moreover, fluency effects 
are typically smaller when the source of fluency is salient (Gellatly et al., 1995). This finding might also inform the present findings regarding the effects of prime duration. For example, Gellatly et al. (1995) demonstrated that identification of a connection between prime and target, rather than prime duration, moderated fluency effects. Thus, with respect to the present research, it is possible that longer prime durations reduce positivity-familiarity effects only when participants are aware of the effect of prime valence on their judgments of the target. To the extent that participants are unaware of this influence, priming effects may increase as a function of affect strength, leading to stronger positivity-familiarity effects for long compared to short prime presentation times. Future research may help to illuminate potential parallels between fluency-familiarity effects and positivity-familiarity effects by investigating interactive effects of prime duration and awareness.

Another factor that might influence the likelihood of misattribution is applicability of activated content to specific target affordances (e.g., Ecker \& Bar-Anan, 2018). With respect to the positivity-familiarity effect, positive affect has been manipulated either contextually (e.g., Garcia-Marques et al., 2004; Phaf \& Rotteveel, 2005) or via features of the target objects (e.g., Corneille et al., 2005; Monin, 2003). Thus, applicability might be high if positive affect is elicited by the object that has to be judged in terms of its familiarity. However, applicability might be low if positive affect stems from a source that is different from the target. In the latter case, the target may need to have features that are conceptually related to positivity, so that overlap between positivity and familiarity is possible. Thus, when positive affect is elicited by contextual stimulus, misattribution of positive affect to familiarity might be influenced by source-target fit. The present set of studies relied on specific prime material (i.e., IAPS; Lang, et al., 2008). Although it seems safe to assume that the IAPS stimuli elicited positive or negative 
affect, we cannot rule out that different prime stimuli would influence the misattribution of positivity to judgments of familiarity differently. Thus, future research may provide deeper insights into this question by using a variety of affective prime stimuli and investigating sourcetarget fit as a potential moderator of positivity-familiarity effects.

\section{Conclusion}

The present research aimed to identify conditions that consistently produce positivityfamiliarity effects and distinguish them from conditions under which positivity-familiarity effects are weaker and less reliable. Overall, we found significant positivity-familiarity effects in seven out of twelve conditions. Nevertheless, Bayes Factor analyses on the combined data suggested that positivity-familiarity effects are quite robust and were not moderated by task context or prime duration. Thus, the present results pose a challenge for extant accounts of positivity-familiarity effects. To the extent that a task context that suggests a normatively accurate response does not enhance analytic processing, it remains an open question what prevented the occurrence of positivity-familiarity effects in earlier studies (Weil, et al., 2017). Yet, to the extent that such a task context does enhance analytic processing, it remains unclear why it did not moderate positivity-familiarity effects in the Bayesian Factor analysis of the combined data. Moreover, to the extent that longer prime presentations reduce misattribution effects by increasing the salience of the primes and prime duration does not moderate positivityfamiliarity effects, it might be questioned whether the underlying mechanism is indeed a misattribution of positivity to judgments of familiarity or whether the effect might be driven by other, yet to be identified processes. Taken together, the present research highlights the importance of investigating the assumed underlying misattribution process of positivityfamiliarity effects and to verify proposed processes by identifying their boundary conditions. 


\section{Open Practices}

All materials and data are available at https://osf.io/3m25w/. 


\section{References}

Alexopoulos, T., Lemonnier, A., \& Fiedler, K. (2017). Higher order influences on evaluative priming: Processing styles moderate congruity effects. Cognition and Emotion, 31, 57-68. https://doi.org/10.1080/02699931.2015.1080666

Baudouin, J. Y., Gilibert, D., Sansone, S., \& Tiberghien, G. (2000). When the smile is a cue to familiarity. Memory, 8, 285-292. https://doi.org/10.1080/09658210050117717

Benjamini, Y., \& Hochberg, Y. (1995). Controlling the false discovery rate: a practical and powerful approach to multiple testing. Journal of the Royal Statistical Society. Series B (Methodological), 289-300. https://www.jstor.org/stable/2346101

Bornstein, R. F. (1989). Exposure and affect: overview and meta-analysis of research, 19681987. Psychological Bulletin, 106, 265-289. https://doi.org/10.1037/0033-2909.106.2.265

Claypool, H. M., Hall, C. E., Mackie, D. M., \& Garcia-Marques, T. (2008). Positive mood, attribution, and the illusion of familiarity. Journal of Experimental Social Psychology, 44, 721-728. https://doi.org/10.1016/j.jesp.2007.05.001

Corneille, O., Monin, B., \& Pleyers, G. (2005). Is positivity a cue or a response option? Warm glow vs. evaluative matching in the familiarity for attractive and not-so-attractive faces. Journal of Experimental Social Psychology, 41, 431-437. https://doi.org/10.1016/j.jesp.2004.08.004

Curran, P. J., \& Hussong, A. M. (2009). Integrative data analysis: The simultaneous analysis of multiple data sets. Psychological Methods, 14, 81-100. http://dx.doi.org/10.1037/a0015914

Dechêne, A., Stahl, C., Hansen, J., \& Wänke, M. (2009). Mix me a list: Context moderates the truth effect and the mere-exposure effect. Journal of Experimental Social Psychology, 45, 
1117-1122. https://doi.org/10.1016/j.jesp.2009.06.019

De Houwer, J., \& Smith, C. T. (2013). Go with your gut! Effects in the Affect Misattribution Procedure become stronger when participants are encouraged to rely on their gut feelings. Social Psychology, 44, 299-302. https://doi.org/10.1027/1864-9335/a000115

Deutsch, R., Kordts-Freudinger, R., Gawronski, B., \& Strack, F. (2009). Fast and fragile: A new look at the automaticity of negation processing. Experimental Psychology, 56, 434-446. https://doi.org/10.1027/1618-3169.56.6.434

Earp, B. D., \& Trafimow, D. (2015). Replication, falsification, and the crisis of confidence in social psychology. Frontiers in Psychology, 6:621. https://doi.org/10.3389/fpsyg.2015.00621

Ecker, Y., \& Bar-Anan, Y. (2018). Applicability increases the effect of misattribution on judgment. Cognition and Emotion. https://doi.org/10.1080/02699931.2018.1498322

Eder, A. B., \& Deutsch, R. (2015). Watch the target! Effects in the affective misattribution procedure become weaker (but not eliminated) when participants are motivated to provide accurate responses to the target. Frontiers in Psychology, 6:1442. https://doi.org/10.3389/fpsyg.2015.01442

Faul, F., Erdfelder, E., Lang, A.-G., \& Buchner, A. (2007). G*Power 3: A flexible statistical power analysis program for the social, behavioral, and biomedical sciences. Behavior Research Methods, 39, 175-191. https://doi.org/10.3758/bf03193146

Freitas, A. L., Azizian, A., Travers, S., \& Berry, S. A. (2005). The evaluative connotation of processing fluency: Inherently positive or moderated by motivational context? Journal of Experimental Social Psychology, 41, 636-644. https://doi.org/10.1016/j.jesp.2004.10.006

Garcia-Marques, T., Mackie, D. M., Claypool, H. M., \& Garcia-Marques, L. (2004). Positivity 
can cue familiarity. Personality and Social Psychology Bulletin, 30, 585-593. https://doi.org/10.1177/0146167203262856

Gawronski, B., \& Ye, Y. (2014). What drives priming effects in the affect misattribution procedure? Personality and Social Psychology Bulletin, 40, 3-15. https://doi.org/10.1177/0146167213502548

Gellatly, A., Banton, P., \& Woods, C. (1995). Salience and awareness in the Jacoby-Whitehouse effect. Journal of Experimental Psychology: Learning, Memory, \& Cognition, 21, 13741379. https://doi.org/10.1037/0278-7393.21.5.1374

Halberstadt, J. (2010). Intuition: Dumb but lucky. Fortuitous affective cues and their disruption by analytic thought. Social and Personality Psychology Compass, 4, 64-76. https://doi.org/10.1111/j.1751-9004.2009.00242.x

Halberstadt, J., \& Catty, S. (2008). Analytic thought disrupts familiarity-based decision making. Social Cognition, 26, 755-765. https://doi.org/10.1521/soco.2008.26.6.755

Housley, M. K., Claypool, H. M., Garcia-Marques, T., \& Mackie, D. M. (2010). “We” are familiar but "It” is not: Ingroup pronouns trigger feelings of familiarity. Journal of Experimental Social Psychology, 46, 114-119. https://doi.org/10.1016/j.jesp.2009.08.011 JASP Team (2018). JASP (Version 0.9) [Computer software].

Jacoby, L. L., \& Kelley, C. M. (1987). Unconscious influences of memory for a prior event. Personality and Social Psychology Bulletin, 13, 314-336. https://doi.org/10.1177/0146167287133003

Jacoby, L. L., \& Whitehouse, K. (1989). An illusion of memory: False recognition influenced by unconscious perception. Journal of Experimental Psychology: General, 118, 126-135. https://doi.org/10.1037//0096-3445.118.2.126 
Jeffreys, H. (1961). Theory of probability (3rd ed.). Oxford: Oxford University Press.

Jones, C. R., Fazio, R. H., \& Olson, M. A. (2009). Implicit misattribution as a mechanism underlying evaluative conditioning. Journal of Personality and Social Psychology, 96, 933-948. https://doi.org/10.1037/a0014747

Lander, K., \& Metcalfe, S. (2007). The influence of positive and negative facial expressions on face familiarity. Memory, 15, 63-69. https://doi.org/10.1080/09658210601108732

Lang, P. J., Bradley, M. M., \& Cuthbert, B. N. (2008). The international affective picture system (IAPS): Technical manual and affective ratings. Gainesville, FL: The Center for Research in Psychophysiology, University of Florida.

Lee, M. D., \& Wagenmakers, E.-J. (2013). Bayesian cognitive modeling: A practical course. New York, NY, US: Cambridge University Press. dx.doi.org/10.1017/CBO9781139087759

Loersch, C., \& Payne, B. K. (2011). The situated inference model an integrative account of the effects of primes on perception, behavior, and motivation. Perspectives on Psychological Science, 6, 234-252. https://doi.org/10.1177/1745691611406921

Maxwell, S. E., Lau, M. Y., \& Howard, G. S. (2015). Is psychology suffering from a replication crisis? What does "failure to replicate” really mean? American Psychologist, 70, 487-498. https://doi.org/10.1037/a0039400

Mierop, A., Hütter, M., Stahl, C., \& Corneille, O. (2018). Does attitude acquisition in evaluative conditioning without explicit CS-US memory reflect implicit misattribution of affect? Cognition and Emotion. https://doi/10.1080/02699931.2018.1435505

Monin, B. (2003). The warm glow heuristic: When liking leads to familiarity. Journal of Personality and Social Psychology, 85, 1035-1048. https://doi.org/10.1037/0022- 
3514.85.6.1035

Montoya, R. M., Horton, R. S., Vevea, J. L., Citkowicz, M., \& Lauber, E. A. (2017). A reexamination of the mere exposure effect: The influence of repeated exposure on recognition, familiarity, and liking. Psychological Bulletin, 143, 459-498. https://psycnet.apa.org/doi/10.1037/bul0000085

Morey, R. D., \& Rouder, J. N. (2018). BayesFactor: Computation of Bayes Factors for common designs. R package version 0.9.12-4.2. https:/CRAN.R-project.org/package=BayesFactor

Murphy, S. T., \& Zajonc, R. B. (1993). Affect, cognition, and awareness: affective priming with optimal and suboptimal stimulus exposures. Journal of Personality and Social Psychology, 64, 723-739. https://doi.org/10.1037//0022-3514.64.5.723

Newell, B. R., \& Shanks, D. R. (2007). Recognising what you like: Examining the relation between the mere-exposure effect and recognition. European Journal of Cognitive Psychology, 19, 103-118. https://doi.org/10.1080/09541440500487454

Oikawa, M., Aarts, H., \& Oikawa, H. (2011). There is a fire burning in my heart: The role of causal attribution in affect transfer. Cognition and Emotion, 25, 156-163. https://doi.org/10.1080/02699931003680061

Open Science Collaboration (2015). Estimating the reproducibility of psychological science. Science, 349(6251), aac4716. https://doi.org/10.1126/science.aac4716

Palan, S., \& Schitter, C. (2018). Prolific. ac-A subject pool for online experiments. Journal of Behavioral and Experimental Finance, 17, 22-27. https://doi.org/10.1016/j.jbef.2017.12.004 
Payne, B. K., Cheng, S. M., Govorun, O., \& Stewart, B. D. (2005). An inkblot for attitudes: Affect misattribution as implicit measurement. Journal of Personality and Social Psychology, 89, 277-293. https://doi.org/10.1037/0022-3514.89.3.277

Payne, B. K. \& Lundberg, K. B. (2014). The Affect Misattribution Procedure: Ten years of evidence on reliability, validity, and mechanisms. Social and Personality Psychology Compass, 8, 672-686. https://doi.org/10.1111/spc3.12148

Peer, E., Brandimarte, L., Samat, S., \& Acquisti, A. (2017). Beyond the Turk: Alternative platforms for crowdsourcing behavioral research. Journal of Experimental Social Psychology, 70, 153-163. https://doi.org/10.1016/j.jesp.2017.01.006

Phaf, R. H., \& Rotteveel, M. (2005). Affective modulation of recognition bias. Emotion, 5, 309318. https://doi.org/10.1037/1528-3542.5.3.309

R Core Team (2018). R: A language and environment for statistical computing. R Foundation for Statistical Computing, Vienna, Austria. https://www.R-project.org/.

Rotteveel, M., \& Phaf, R. H. (2007). Mere exposure in reverse: Mood and motion modulate memory bias. Cognition and Emotion, 21, 1323-1346. https://doi.org/10.1080/02699930701438319

Ruys, K. I., Aarts, H., Papies E. K., Oikawa, M. \& Oikawa, H. (2012). Perceiving an exclusive cause of affect prevents misattribution. Consciousness and Cognition, 21, 1009-1015. https://doi.org/10.1016/j.concog.2012.03.002

Stroebe, W., \& Strack, F. (2014). The alleged crisis and the illusion of exact replication. Perspectives on Psychological Science, 9, 59-71. https://doi.org/10.1177/1745691613514450

Van Bavel, J. J., Mende-Siedlecki, P., Brady, W. J., \& Reinero, D. A. (2016). Contextual 
sensitivity in scientific reproducibility. Proceedings of the National Academy of Sciences, 113, 6454-6459. https://doi.org/10.1073/pnas.1521897113

Verde, M. F., Stone, L. K., Hatch, H. S., \& Schnall, S. (2010). Distinguishing between attributional and mnemonic sources of familiarity: The case of positive emotion bias. Memory \& Cognition, 38, 142-153. https://doi.org/10.3758/mc.38.2.142

Weil, R., Palma, T. A., \& Gawronski, B. (2017). At the boundaries of misattribution: Does positivity influence judgments of familiarity in the Affect Misattribution Procedure? Experimental Psychology, 64, 369-386. https://doi.org/10.1027/1618-3169/a000379

Westerman, D. L. (2008). Relative fluency and illusions of recognition memory. Psychonomic Bulletin \& Review, 15, 1196-1200. https://doi.org/10.3758/pbr.15.6.1196

Westerman, D. L., Lloyd, M. E., \& Miller, J. K. (2002). The attribution of perceptual fluency in recognition memory: The role of expectation. Journal of Memory and Language, 47, 607617. https://doi.org/10.1016/s0749-596x(02)00022-0

White, G. L., \& Knight, T. D. (1984). Misattribution of arousal and attraction: Effects of salience of explanations of arousal. Journal of Experimental Social Psychology, 20, 5564. https://doi.org/10.1016/0022-1031(84)90012-x

Whittlesea, B. W., \& Leboe, J. P. (2003). Two fluency heuristics (and how to tell them apart). Journal of Memory and Language, 49, 62-79. https://doi.org/10.1016/s0749596x(03)00009-3

Whittlesea, B. W., \& Price, J. R. (2001). Implicit/explicit memory versus analytic/nonanalytic processing: Rethinking the mere exposure effect. Memory \& Cognition, 29, 234-246. https://doi.org/10.3758/bf03194917

Whittlesea, B. W. A., \& Williams, L. D. (2000). The source of feelings of familiarity: The 
discrepancy-attribution hypothesis. Journal of Experimental Psychology: Learning, Memory, and Cognition, 26, 547-565. https://doi.org/10.1037//0278-7393.26.3.547

Whittlesea, B. W., \& Williams, L. D. (2001). The discrepancy-attribution hypothesis: I. The heuristic basis of feelings and familiarity. Journal of Experimental Psychology: Learning, Memory, and Cognition, 27, 3-13. https://doi.org/10.1037//0278-7393.27.1.3

Winkielman, P., Schwarz, N., Fazendeiro, T., \& Reber, R. (2003). The hedonic marking of processing fluency: Implications for evaluative judgment. In J. Musch, \& K. C. Klauer (Eds.), The psychology of evaluation: Affective processes in cognition and emotion (pp. 189-217). Mahwah, NJ: Erlbaum.

Zajonc, R. B. (1968). Attitudinal effects of mere exposure. Journal of Personality and Social Psychology, 9, 1-27. https://doi.org/10.1037/h0025848 


\section{Acknowledgments}

This work was supported by a seed-corn grant from the European Association of Social Psychology. 
Table 1. Bayes Factors for main effects and interactions of familiarity judgments for combined analyses.

\begin{tabular}{ll}
\hline Main Effects and Interactions & Bayes Factors \\
\hline Combined analysis of Experiment 1, 2, and 5 & \\
Prime Valence & $\mathrm{BF}_{10}=215617.352$ \\
Task Context & $\mathrm{BF}_{10}=.132$ \\
Prime Valence $\times$ Task Context & $\mathrm{BF}_{10}=.106$ \\
Combined analysis of Experiment 3, 4, and 5 & \\
Prime Valence & $\mathrm{BF}_{10}=5890.218$ \\
Prime Duration & $\mathrm{BF}_{10}=.084$ \\
Prime Valence $\times$ Prime Duration & $\mathrm{BF}_{10}=.0056$ \\
\hline
\end{tabular}


Table 2. Summary of results in Experiments 1-5. Emergence of a significant positivityfamiliarity effect as a function of bogus stimuli in prior subliminal presentation task (judgmentrelevant vs. judgment-irrelevant), target judgment (familiar/unfamiliar vs. old/new), and prime presentation times (20ms vs. $75 \mathrm{~ms}$ vs. $200 \mathrm{~ms}$ ).

\begin{tabular}{|c|c|c|c|c|}
\hline & Bogus Stimuli & Target Judgment & $\begin{array}{c}\text { Prime } \\
\text { Presentation }\end{array}$ & $\begin{array}{c}\text { Positivity- } \\
\text { Familiarity Effect }\end{array}$ \\
\hline \multirow[t]{2}{*}{ Exp. 1} & $\begin{array}{l}\text { judgment- } \\
\text { relevant }\end{array}$ & familiar/unfamiliar & $75 \mathrm{~ms}$ & Yes \\
\hline & $\begin{array}{l}\text { judgment- } \\
\text { irrelevant }\end{array}$ & familiar/unfamiliar & $75 \mathrm{~ms}$ & Yes \\
\hline \multirow[t]{2}{*}{ Exp. 2} & $\begin{array}{l}\text { judgment- } \\
\text { relevant }\end{array}$ & familiar/unfamiliar & $75 \mathrm{mc}$ & No \\
\hline & $\begin{array}{l}\text { judgment- } \\
\text { relevant }\end{array}$ & old/new & $75 \mathrm{~ms}$ & No \\
\hline \multirow[t]{2}{*}{ Exp. 3} & - & familiar/unfamiliar & $20 \mathrm{~ms}$ & No \\
\hline & - & familiar/unfamiliar & $200 \mathrm{~ms}$ & Yes \\
\hline \multirow[t]{2}{*}{ Exp. 4} & - & familiar/unfamiliar & $20 \mathrm{~ms}$ & Yes \\
\hline & - & familiar/unfamiliar & $200 \mathrm{~ms}$ & Yes \\
\hline \multirow[t]{4}{*}{ Exp. 5} & $\begin{array}{l}\text { judgment- } \\
\text { relevant }\end{array}$ & old/new & $20 \mathrm{~ms}$ & No \\
\hline & $\begin{array}{l}\text { judgment- } \\
\text { relevant }\end{array}$ & old/new & $200 \mathrm{~ms}$ & No \\
\hline & $\begin{array}{l}\text { judgment- } \\
\text { irrelevant }\end{array}$ & familiar/unfamiliar & $20 \mathrm{~ms}$ & Yes \\
\hline & $\begin{array}{l}\text { judgment- } \\
\text { irrelevant }\end{array}$ & familiar/unfamiliar & $200 \mathrm{~ms}$ & Yes \\
\hline
\end{tabular}




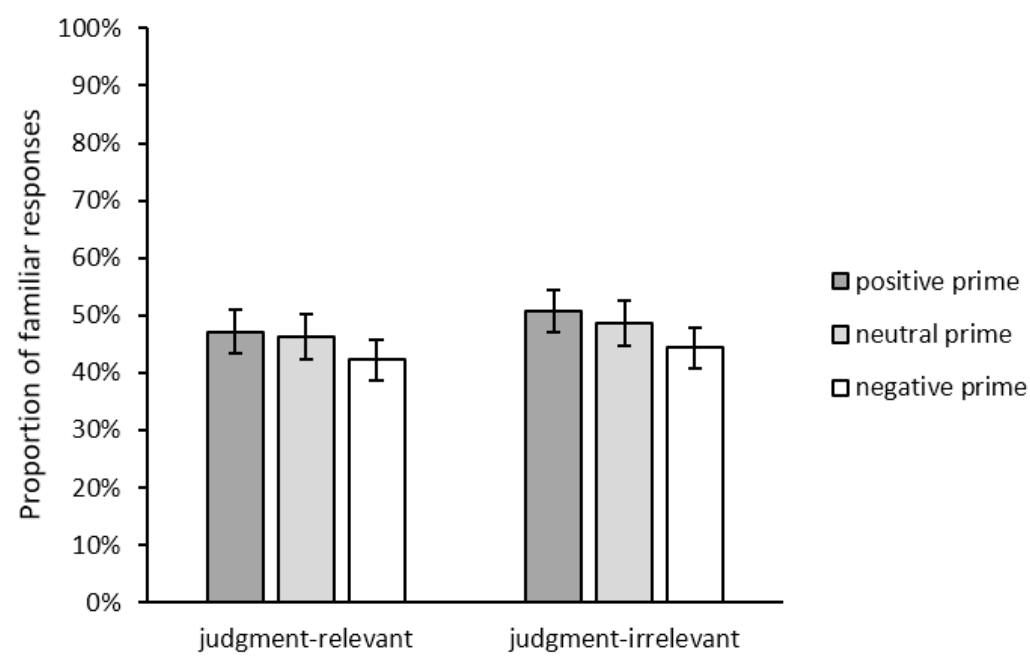

Figure 1. Mean percentages of "familiar" judgments as a function of prime valence (positive, neutral, negative) and bogus stimuli in the subliminal presentation task (judgment-relevant vs. judgment-irrelevant), Experiment 1. Error bars depict 95\% confidence intervals.

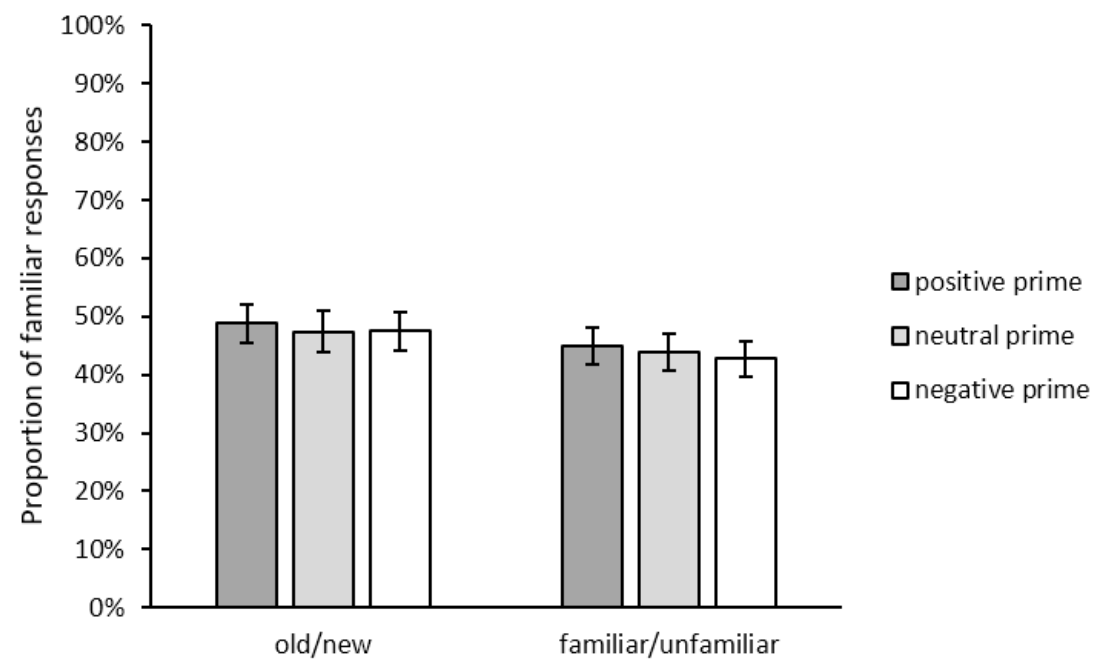

Figure 2. Mean percentages of "familiar" judgments as a function of prime valence (positive, neutral, negative) and target judgment (old/new vs. familiar/unfamiliar), Experiment 2. Error bars depict 95\% confidence intervals. 


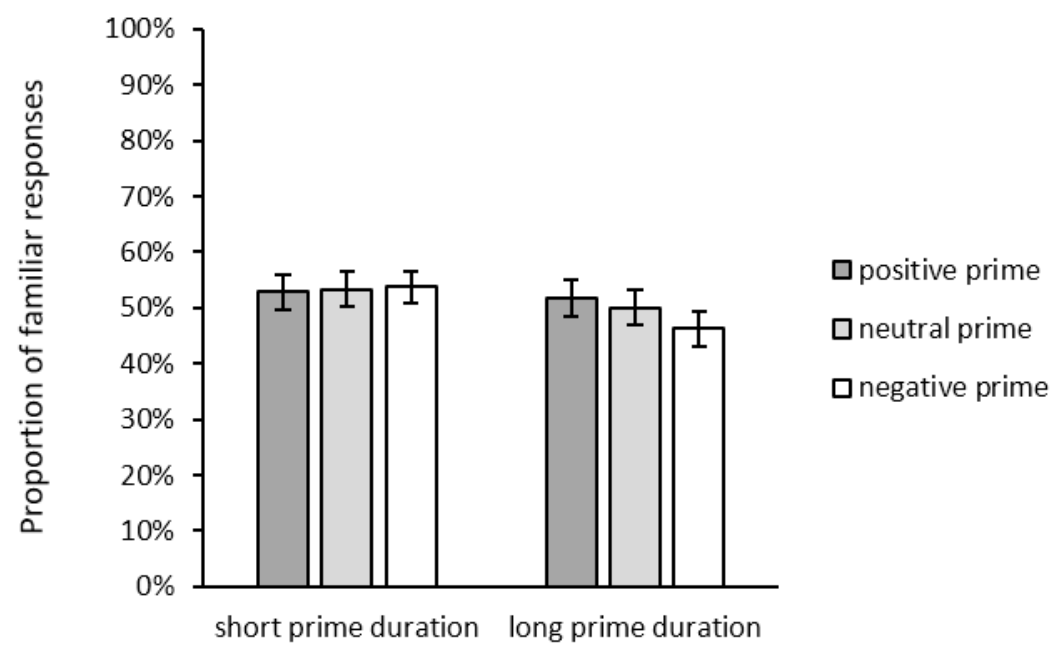

Figure 3. Mean percentages of "familiar" judgments as a function of prime valence (positive, neutral, negative) and prime duration (short vs. long), Experiment 3. Error bars depict 95\% confidence intervals.

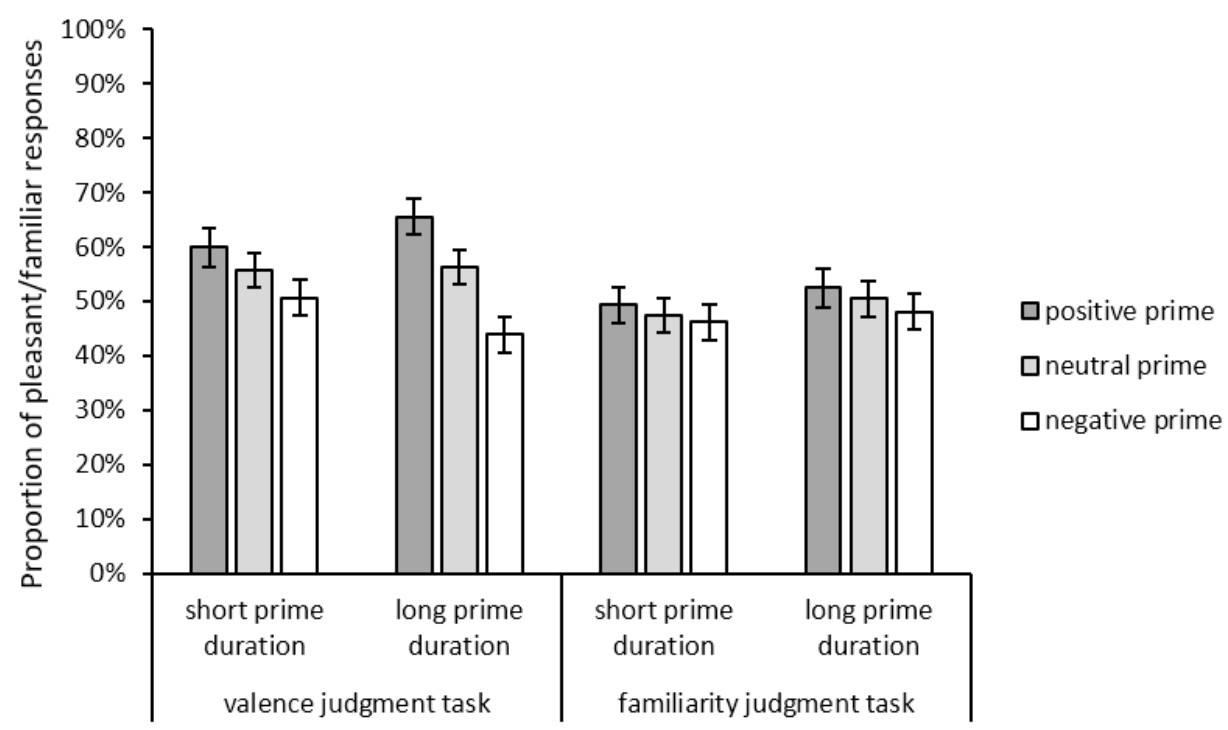

Figure 4. Mean percentages of "pleasant/familiar" judgments as a function of prime valence (positive, neutral, negative), prime duration (short vs. long), and target judgment (valence vs. familiarity), Experiment 4. Error bars depict 95\% confidence intervals. 


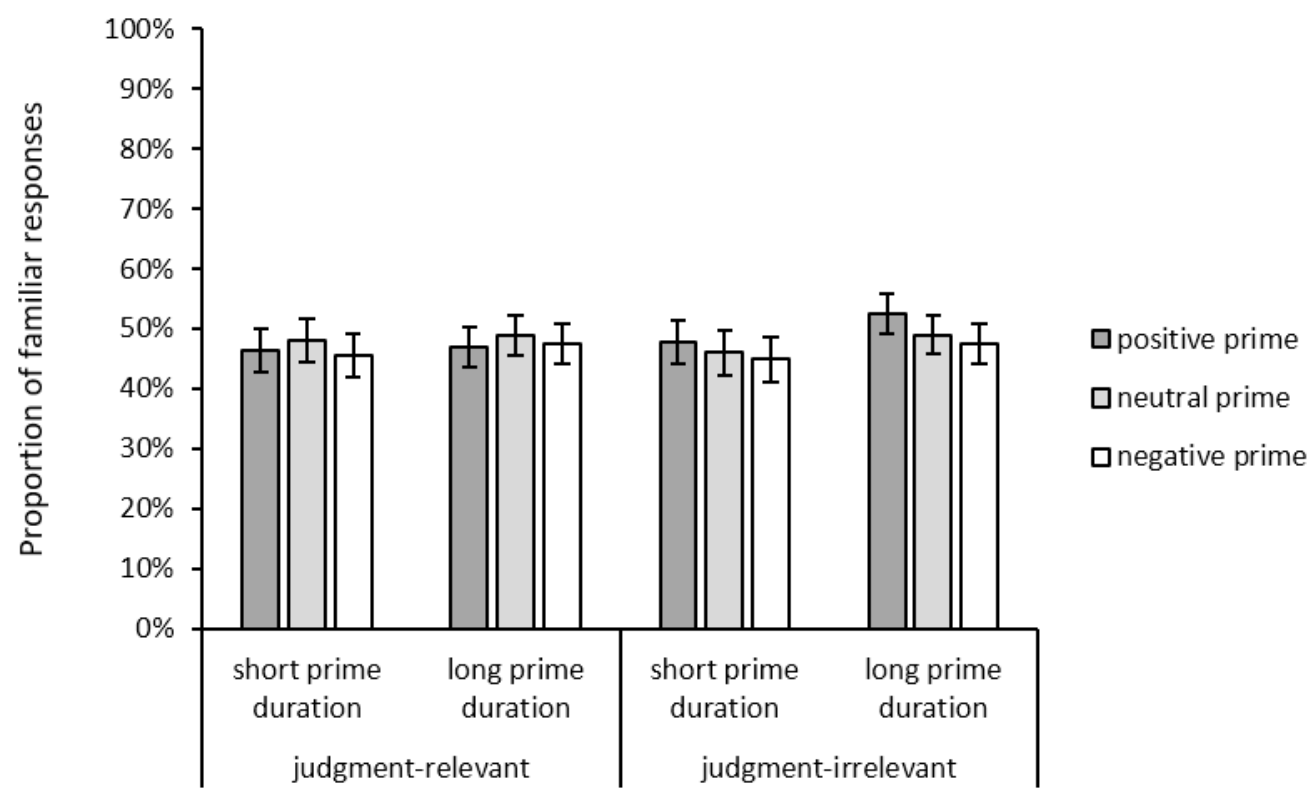

Figure 5. Mean percentages of "familiar" judgments as a function of prime valence (positive, neutral, negative), prime duration (short vs. long), and task context (judgment-relevant vs. judgment-irrelevant), Experiment 5. Error bars depict 95\% confidence intervals. 